\title{
Characterization of non-structural poly (vinyl) chloride, rock wool and medium density fiberboard waste composites
}

\begin{abstract}
Seeking to combine thermal comfort with the reuse of difficult degradation materials, which generate large volumes discarded in landfills, this study aims to use Poly (vinyl) chloride (PVC), rock wool and Medium Density Fiberboard (MDF) waste in the manufacture of nonstructural boards in civil construction. The samples were prepared by varying the formulations in order to find the one that has better thermal conductivity contribution. The work, still in progress, presents lower swelling results to the average of insulating materials, and water absorption of the plates lifted by the use of sodium bicarbonate; used in the composition to increase the void ratio. Although, separately, the three materials present low thermal conductivity; when mixed the conductivity tends to increase, but still remains below the average value of other sealing materials used in civil construction.
\end{abstract}

Keywords: waste, PVC, rock wool, MDF, non-structural composite, thermal conductivity, water absorption, void ratio, swelling test, low density composite
Volume 3 Issue 6 - 2019

\author{
Marco Canale Sirena, Aline Zini, Luiza Rech \\ Brancher, Mara Zeni, Maria Fernanda de \\ Oliveira Nunes, Ana Maria Coulon Grisa \\ Laboratório de Pesquisa e Materiais, University of Caxias do \\ Sul, Brazil
}

Correspondence: Ana Maria Coulon Grisa, Laboratório de Pesquisa e Materiais, University of Caxias do Sul, Brazil, Fax (54)32182100,Tel (54)999452360,Email amcrisa@ucs.br

Received: August 29, 2019 | Published: November II, 2019

\section{Introduction}

Taking into account sustainable development concept spread at the end of the 20th century, new composite materials are introduced in modern countries to promote wood and plastic waste. ${ }^{1}$ Thermal insulation plays an important role in contributing to the energy savings in the building by heat gains and losses through the building envelope. ${ }^{2}$ A study reported that effective building insulation alone will save over one hundred times the impacts of carbon foot print from material usage and disposal, irrespectively of the materials used. ${ }^{3}$ In all countries, regardless of their level of development, wood and Poly (vinyl) chloride (PVC), in civil construction, generate significant amounts of waste without an ecological destination.1 PVC represents a promising source of raw material for the development of composites, especially because of the large volume and low cost of this material. ${ }^{4}$ These composites have several advantages, including low cost, low density, low manufacturing energy, compared to other thermoplastic polymer composites. ${ }^{5}$

In other recent studies, it is possible to observe the quantity issues of alternative rock wool materials available in the market to meet the demand for the building sector, because rock wool materials are very good insulators. ${ }^{6}$ Several countries have made efforts to solve this problem of materials destination and eco efficiency by trying to recycle urban and industrial waste materials. ${ }^{7}$ With this increasing demand for waste use, there is the possibility of reuse industrial waste, contributing to the industry production process and construction area, developing composites which can provide thermal insulation and be a sustainable alternative. Furniture industries of southern Brazil generate around 253t/month of solid waste basically formed of Medium Density Fiberboard (MDF), PVC e rock wool. Thus, in this study, the potential for the mixture of these materials for the development of new filler composite was tested. The effect of materials proportions, water absorption and thermal conductivity of the samples was investigated and their potential use in buildings and in the furniture industry has been evaluated.

\section{Methodology}

\section{Characterization of the materials}

In this work it was used shredded PVC (Polyvinyl chloride), powder rock wool, and powder MDF (Medium-Density Fiberboard) waste, donated by furniture industries of the Southern Brazil, Elastin, donated by Bayer in Brazil, tin octanoate, commercial Sodium Bicarbonate and distilled water. PVC waste was ground in a mill of knives MARCONI MA580 until the format of $\pm 3 \mathrm{~mm}$ by $1 \mathrm{~mm}$ strips.

\section{Preparing the composite}

The composites formulations containing waste and other components were prepared according to the proportions shown in Table 1. The components for the plates manufacture, and further characterization, were homogenized in an electromechanical mixer PAVITEST for $5 \mathrm{~min}$. After homogenization, the obtained mixture was poured into $20 \times 20 \times 1 \mathrm{~cm}$ molds, and submitted to $8 \mathrm{t}$ of pressure for $10 \mathrm{~min}$ in an ELETRON press at $75^{\circ} \mathrm{C}$. 
Table I Components of the composite

\begin{tabular}{ll}
\hline Materials & Quantity \\
\hline PVC $(\mathrm{g})$ & $50-90$ \\
MDF $(\mathrm{g})$ & $40-50$ \\
Rock Wool $(\mathrm{g})$ & $40-50$ \\
Elastan $(\mathrm{ml})$ & $45-50$ \\
Sodium Bicarbonate $(\mathrm{g})$ & $20-25$ \\
Tin Octanoate $(\mathrm{ml})$ & $0,5-1$ \\
Distilled Water $(\mathrm{ml})$ & $10-20$
\end{tabular}

\section{Characterization of samples}

Swelling and water absorption tests: The swelling and water absorption tests were performed according to the NBR 14810-3 standard. Previously the samples were dried in an oven QUIMIS, and with the aid of a caliper (MITUTOYO). It was determined the thickness and the mass of the specimens with the aid of a scalimeter. After determining the characteristics of the samples, they were kept submerged in water in a room with $23^{\circ} \mathrm{C}\left( \pm 2^{\circ} \mathrm{C}\right)$ of temperature for 24 hours, subsequently it was performed the weighing and measuring of the samples. The swelling and water absorption of the composite was calculated according to Equation 1 and 2.

$$
I=\left[\left(\frac{E 1-E 0}{E 0}\right) 100\right]
$$

$$
M=\left[\left(\frac{M 1-M 0}{M 0}\right) 100\right]
$$

Where $\mathrm{I}=$ Body swelling, in percentage; $\mathrm{E}_{1}=$ The thickness of the body after immersion time, in $\mathrm{mm} ; \mathrm{E}_{0}=$ The thickness of the specimen before immersion, in $\mathrm{mm}$; $\mathrm{A}=$ Water absorption, in percentage; $\mathrm{M}_{1}=$ Body mass after the immersion time, in $\mathrm{g}$ and $\mathrm{M}_{0}=$ Body mass before immersion time, in $\mathrm{g}$.

Thermal Conductivity Test: The thermal conductivity was determined according to the ISO 8302 procedures, for determining the thermal resistance at steady state heat transfer. The mounting configuration of the adopted devices was symmetrical with two flow meters and a specimen (Figure 1). The specimen is disposed between two flow meters, surrounded by the hot plate - on the upper face - and the cold plate - on the lower face. The hot plate was composed of a resistor with a temperature of $70^{\circ} \mathrm{C}$. After 30 minutes, the temperature recording was performed every 60 seconds until the cold plate temperature stability, for five measurements. The entire system was wrapped in a thermal blanket fiber, to avoid possible interference from the external environment. The thermal conductivity determination $(\lambda)$ was conducted based on the temperature difference $(\Delta t)$ between the two faces of the sample, according to Equation 3.

$$
\lambda=Q / A\left(\frac{\Delta t}{e}\right)
$$

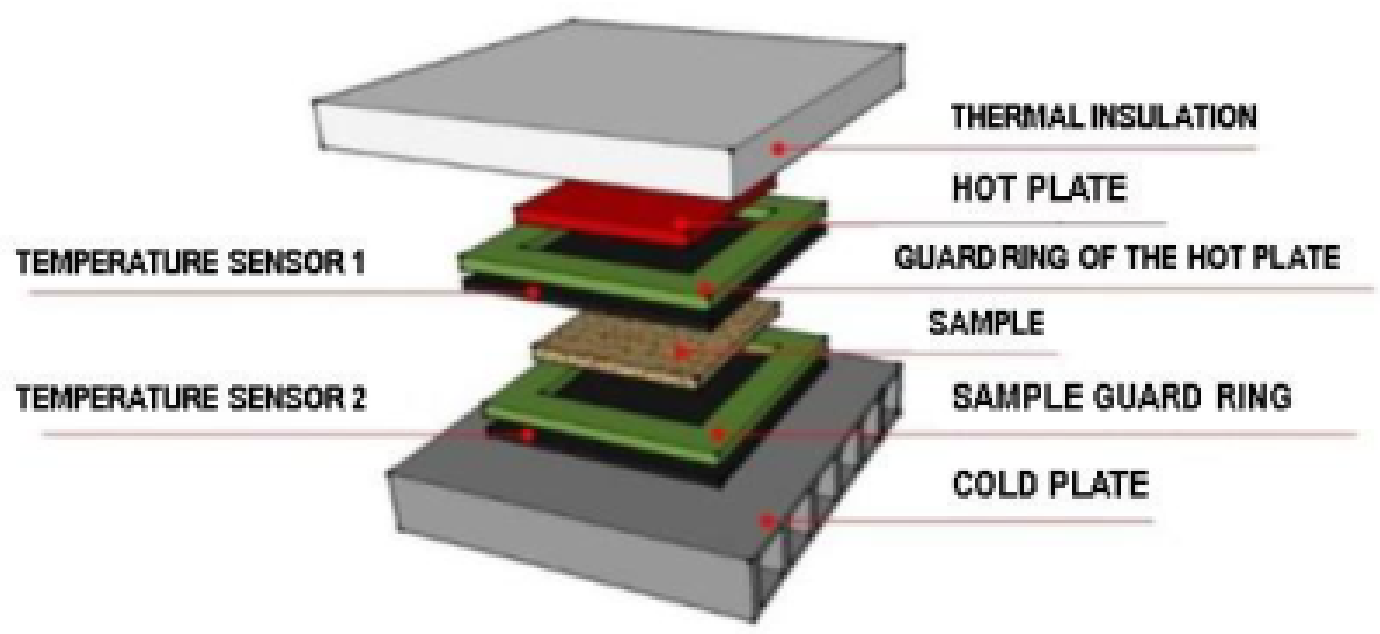

Figure I System for determining the samples thermal conductivity.

Where: $\lambda=$ thermal conductivity $[\mathrm{W} /(\mathrm{mK})] ; \mathrm{Q}=$ heat flux density $[\mathrm{W} /(\mathrm{mK})] ; \mathrm{A}=$ Plate area $\left(\mathrm{m}^{2}\right) ; \Delta \mathrm{t}=$ Temperature gradient $(\mathrm{K})$; e-Board thickness (m);

Swelling and water absorption tests: Table 2 shows the results of swelling and water absorption tests of the composites. High wood flour content $(20 \%)$, leads to high water absorption rates ${ }^{8}$ as seen in the results after the test (Table 2). The samples water absorption is due, mainly, because the wood is naturally hydrophilic and the PVC has a negligible water absorption. ${ }^{9}$ Usually, the wood plastic composites absorb water in function of its natural hygroscopic characteristic or because of the voids present in the polymer interface with the wood, occurring water penetration in the voids by diffusion. ${ }^{9}$ The board has an average swelling of $1,34 \%$, which is up to $14 \%$ below the average for MDF panels and up to $19 \%$ lower than the swelling of rock wool.10 The variation between the three samples in swelling and water absorption results can be explained by the heterogeneity of this type of composite. ${ }^{10}$ 
Table 2 Swelling and water absorption results of the composite (in triplicate)

\begin{tabular}{lll}
\hline Sample & Swelling (\%) & Water absorption (\%) \\
\hline I & 1,46 & 57,25 \\
& & 69,43 \\
2 & 0,33 & \\
3 & 2,23 & 41,46
\end{tabular}

Thermal Conductivity Test: Table 3 shows the samples thermal conductivity and resistivity results. The thermal insulation properties of the samples were measured in terms of the thermal conductivity. Lower the thermal conductivity better is the insulation property. Low values of the thermal conductivity imply higher resistance to conduction of the heat through the material. It creates a barrier between the surrounding environment and the samples. ${ }^{12}$ The assayed samples showed initially a temperature rise, with a temperature difference between the plates $(\Delta \mathrm{t})$ on average $20^{\circ} \mathrm{C}$ in 30 minutes. Regarding the obtained results the use of composite with MDF, rock wool and PVC residues, would not be indicated as the only way to fill a construction system, due to the low thermal insulation obtained in a short time. The high thermal conductivity of the studied composite is probably due to the significant MDF volume in the samples proportion, considering that the average conductivity of materials such as wood and its derivatives is approximately $\left(0,12 \mathrm{~W} \cdot \mathrm{m}^{-1} \cdot{ }^{\circ} \mathrm{C}^{-1}\right) \cdot{ }^{13}$ Although not to be considered a thermal insulating material, it presents a proportional thermal conductivity to materials such as aluminum $\left(210 \mathrm{~W} \cdot \mathrm{m}^{-1} \cdot{ }^{\circ} \mathrm{C}^{-1}\right)$ and glass $\left(1,15 \mathrm{~W} \cdot \mathrm{m}^{-1} \cdot{ }^{\circ} \mathrm{C}^{-1}\right)$. It also presents lower thermal conductivity than ceramic brick, which is routinely used isolated in sealing systems without the aid of thermal blankets. ${ }^{13}$

Table 3 Results of 3 samples of thermal conductivity and resistivity

\begin{tabular}{lllll}
\hline $\mathbf{Q}(\mathrm{W} / \mathrm{mK})$ & $\Delta \mathrm{t}(\mathbf{k})$ & $\mathbf{e}(\mathrm{m})$ & $\boldsymbol{\lambda}(\mathrm{W} / \mathrm{mK})$ & $\mathbf{R}(\mathbf{m K} / \mathrm{W})$ \\
\hline 48,3 & 20,4 & & 0,592 & 0,017 \\
& & 0,01 & &
\end{tabular}

\section{Conclusion}

In the present work, it has been experimented a mixture of MDF, PVC and rock wool residues from a local industry; to form a low density composite with good thermal insulation, to be used in nonstructural projects in civil construction and as a filler composite for furniture industries. This work showed that this composite contains a high water absorption parameter when compared to other materials used with the same thermal insulation purpose. Wood is a hydrophilic material, and due to its proportion in the composite, collaborated with the material water absorption and swelling, despising the waterproof feature of the PVC used in the mix. The average plate swelling was less than the average for MDF panels. The thermal conductivity value was above the insulating materials most widely used in construction; nevertheless, it is still below materials used as a seal, such as ceramic bricks and glass. Thus, there is a feasible solution using the composite as walls and furniture filler, working in aid of these sealing materials to reduce their conductivity. A proper disposal of these materials has led to a composite that can be developed and widely exploited by the very industries in southern Brazil, which generate these waste, in view of the large volume problem and the current allocation to landfills.
The product has favorable characteristics such as low density, besides not have a structural purpose, which facilitates their insertion in the market. These aspects lead to a product that helps to develop the region in an eco-efficient way.

\section{Funding}

None.

\section{Acknowledgments}

None.

\section{Conflicts of interest}

The authors declare no conflict of interest.

\section{References}

1. Agoua E, Allognon-Houessou E, Adjovi E, et al. Thermal conductivity of composites made of wastes of wood and expanded polystyrene. Construction and Building Materials. 2013;41:557-562.

2. Al-Houmoud, MS. Performance characteristics and practical applications of common building thermal insulation materials. Buiding and Environment. 2005;40:353-366.

3. Schmidt AC, Jensen AA, Clausen AU, et al. A comparative life cycle assessment of building insulation products made of stone wool,paper wool and flax. LCA Case Studies. 2004;9:53-66.

4. Selke SE, Wichman I. Wood fiber/polyolefin composites. Composites Part A: Applied Science and Manufacturing. 2004;35:321-326.

5. Kim H, Lee B, Choi S, et al. The effect of types of maleic anhydridegrafted polypropylene (MAPP) on the interfacial adhesion properties of bio-flour-filled polypropylene composites. Composites Part A: Applied Science and Manufacturing. 2007;38:1473-1482.

6. Corscadden KW, Biggs JN, Stiles DK. Sheep's wool insulation: a sustainablealternative use for a renewable resource? Resources, Conservation and Recycling. 2014;86:9-15.

7. Adhikary KB, Pang S, Staiger MP. Dimensional stability and mechanical behaviour of wood-plastic composites based on recycled and virgin high-density polyethylene (HDPE). Composites Part B: Engineering. 2008;39:807-815.

8. Espert A, Vilaplana F, Karlsson S. Comparison of water absorption in natural cellulosic fibres from wood and one-year crops in polypropylene composites and its influence on their mechanical properties. Composites A: Applied Science and Manufacturing. 2004;35:1267-1276.

9. Najafi SK, Kiaefar A, Hamidina E. Water absorption behavior of composites from sawdust and recycled plastics. Journal of Reinforced Plastics and Composites. 2007;26:341-348.

10. Eleotério JR, Mario Tomazello Filho, Geraldo Bortoletto Júnior Propriedades físicas e mecânicas de painéis MDF de diferentes densidades e teores de resina. Ciencia Florestal. 2000;10(2).

11. Muszynski L. Imaging wood plastic composites (WPCs): x-ray computed tomography, a few other promising techniques, and why we should pay attention. Bio Resources. 2009;4:1210-1221.

12. Patnaik A, Mvubu M, Muniyasamy S, et al. Thermal and sound insulation materials from waste wool and recycled polyester fibers and their biodegradation studies. Energy Buildings. 2015;92:161-169.

13. Navroski MC, Lippert DB, Camargo L, et al. Avaliação do isolamento térmico de três diferentes materiais usados na construção e preenchimento de paredes externas. Ciência da Madeira. 2010;1:41-51. 